\title{
SUPPLEMENTATION IN VEGETARIAN PREGNANT: NUTRIENTS AND VITAMINS THAT REQUIRE MORE ATTENTION
}

\section{Fernanda de Luca Almeida*1, Carlos Alberto Nogueira-de-Almeida ${ }^{2,3}$, Idiberto José Zotarelli Filho $^{2,4,5}$ and Durval Ribas Filho ${ }^{2,4}$}

\begin{abstract}
${ }^{1}$ ABMV - Associação Brasileira dos Médicos Vegetarianos/Brazilian Association of Vegetarian Doctors, President, Rio de Janeiro, Brazil; ${ }^{2}$ Associação Brasileira de Nutrologia (ABRAN)/Brazilian Association of Nutrology, Catanduva/SP, Brazil

${ }^{3}$ Federal University of Sao Carlos, São Paulo, Brazil; ${ }^{4}$ FACERES - Medical SchoolofSao Jose do Rio Preto/SP, Brazil;

5Zotarelli-Filho Scientific Work, Sao Jose do Rio Preto/SP, Brazil
\end{abstract}

\begin{tabular}{|c|c|}
\hline ARTICLE INFO & ABSTRACT \\
\hline Article History: & \multirow{7}{*}{$\begin{array}{l}\text { This article is a review of the nutritional aspects of vegetarian diets (including vegan) during } \\
\text { pregnancy, pointing out the aspects that require more attention and where there is a risk of } \\
\text { deficiency. This article contains recommendations made from the current literature. The } \\
\text { bibliographical survey was carried out on the bases PubMed, Scopus, Web of Science and } \\
\text { Embase, Cochrane, Ovid, Periodicos.com, Harvard Library, and Google Scholar. Conclusion: } \\
\text { Vegetarian diets, when well planned, provide all the necessary nutrients to pregnant women and } \\
\text { promote a healthy pregnancy and adequate fetal growth and development. }\end{array}$} \\
\hline Received $10^{\text {th }}$ March, 2021 & \\
\hline Received in revised form & \\
\hline $20^{\text {th }}$ April, 2021 & \\
\hline Accepted $14^{\text {th }}$ May, 2021 & \\
\hline Published online $30^{\text {th }}$ June, 2021 & \\
\hline & \\
\hline
\end{tabular}

Vegetarianism. Veganism.

Vegetarian diets. Vegan diets.

Vegan pregnancy. Nutrients. Vitamins.

*Corresponding author:

Fernanda de Luca Almeida.

Copyright (C) 2021, Fernanda de Luca Almeida et al. This is an open access article distributed under the Creative Commons Attribution License, which permits unrestricted use, distribution, and reproduction in any medium, provided the original work is properly cited.

Citation: Fernanda de Luca Almeida, Carlos Alberto Nogueira-de-Almeida, Idiberto José Zotarelli Filho and Durval Ribas Filho. 2021. "Supplementation in vegetarian pregnant: nutrients and vitamins that require more attention”, International Journal of Development Research, 11, (06), 47973-47976.

\section{INTRODUCTION}

The pregnant woman's nutrition is extremely important for maternal health and is essential for optimal fetal growth and development. Environmental factors and lifestyle during pregnancy are responsible for determining the risk of the child developing chronic diseases in adulthood. A strict vegetarian diet when well planned is fully capable of meeting the nutritional demands of pregnant women and women during the breastfeeding phase [1-6]. But what would a well-planned vegetarian diet be? How do we go about meeting all nutritional needs using only plant foods? Which vitamins and minerals need to be supplemented? Therefore, the present study aimed to review the nutritional aspects of vegetarian diets (including vegan) during pregnancy, pointing out the aspects that require more attention and where there is a risk of deficiency.

\section{METHODS}

Clinical studies were included (case reports, retrospective, prospective and randomized trials) with qualitative and quantitative analysis. Initially, the keywords were determined by searching the DeCS tool (Descriptors in Health Sciences, BIREME base) and later verified and validated by MeSh system (Medical Subject Headings, the US National Library of Medicine) in order to achieve consistent search.

Mesh Terms: The descriptors included were Vegetarianism; Veganism; Vegetarian diets; Vegan diets; Vegan pregnancy; Nutrients and Vitamins.The literature search wasconducted through online databasesPubmed, Scopus, Web of Science e Embase, Cochrane, Ovid, Periodicos.com, Harvard Library and Google Scholar. The risk of BIAS in the present study was not analyzed.

Series of Articles and Eligibility: A total of 79 articles were found involving the MeSH Terms. Initially, it was held the exclusion existing title and duplications in accordance with the interest described this work. After this process, the summaries were evaluated and a new exclusion was held. A total of 65 articles were evaluated in full, and 43 were included and discussed in this study.

\section{Development and Literature Review}

Well Planned Vegetarian Food: The vegetarian diet covers a huge variety of foods rich in macro and micronutrients, antioxidants, and phytochemicals: vegetables, legumes, whole grains, legumes, oilseeds, seeds, and fruits but to be considered balanced you need to 
follow some criteria $[1,2]$. In the past and even today we see many poorly planned diets being characterized as vegetarian simply because they do not include meat, but when analyzed more carefully, we observe many deficiencies and restrictions that do not happen when we refer to a strict balanced vegetarian diet [3-6]. A strictly balanced vegetarian diet should prioritize whole and/or minimally processed foods; all food groups (vegetables, legumes, fats, fruits, cereals, and tubers) must be present daily, the recommended total calories must be reached, calcium-rich foods must be consumed daily, daily vitamin D needs must be guaranteed by adequate sun exposure or supplementation (vitamin D3 from lichen or vitamin D2) and vitamin B12 should be supplemented [1,7]. Vegetable fats should be very well chosen, including sources of omega 3, such as flaxseed oil and flaxseed and chia seeds, prioritizing mono-unsaturated oils such as olive oil, and avoiding trans and saturated fats (coconut and palm oils).Only if all these criteria are present can we say that a strict vegetarian diet is well planned and will be able to provide all the nutritional needs of pregnant women and breastfeeding women [1].

Vegetarian and Pregnant Women: Pregnant and lactating women can fully satisfy their nutritional needs with a strict vegetarian diet that includes varied foods and calcium and B12 supplementation, either through the consumption of foods fortified with these nutrients or through the use of supplements prescribed by a trained physician [1-6]. The adoption of a strict vegetarian diet during pregnancy can also contribute to reduce the risks of developing cardiovascular diseases and gestational diabetes, improve the lipid profile, decrease the body mass index (BMI) and decrease blood pressure levels $[2,8$, $9,10]$. The breast milk of strict vegetarian mothers who follow a wellplanned and balanced diet and who supplement vitamin B12 manages to meet all the nutritional demands of the infant until 6 months of life when then complementary feeding should be started $[3,11,12]$.

Calories: Pregnant women need to consume a wide variety of foods to meet their caloric and nutritional needs and achieve the recommended weight gain $[13,14]$. In the 1 st trimester, the energy expenditure of the pregnant woman is the same as that of the nonpregnant woman and in the 2 nd and $3 r d$ trimester there is an increase of $340 \mathrm{Kcal}$ and $452 \mathrm{kcal}$ per day respectively [14]. Some strict vegetarian pregnant women may have difficulty gaining weight due to the high consumption of low-calorie, fiber-rich plant foods that provide greater satiety. In these cases, the simple orientation of prioritizing nutritionally more dense foods (legumes, nuts, use of olive oil to season vegetables) is enough in most cases.Calorierestricted diets compromise not only the weight gain of the pregnant woman and the fetus, but also provide few micronutrients [14].

Proteins: All essential amino acids can be found in a strict vegetarian diet and if there is a good variety of foods throughout the day, there is no need to combine different protein sources in the same meal. The combination of cereal with a legume is an easy way to achieve the necessary amount of essential amino acids since the limiting amino acid in the cereal is usually abundant in the legume and vice versa $[2,15]$. In a strict vegetarian diet, the best protein sources are legumes and oilseeds, but all foods of plant origin provide protein and the recommended amount of protein is easily reached if the daily caloric content is reached [2]. During the 1st trimester, the protein requirements are the same as those recommended for a vegetarian adult, which in practice corresponds to the daily intake of $1 \mathrm{~g}$ of protein per kilogram of weight $(25 \%$ more than an omnivorous adult due to the lower digestibility of vegetables). In the 2 nd and $3 \mathrm{rd}$ trimesters, there is a greater protein demand due to the increase in fetal metabolism, and an increase in daily consumption of $25 \mathrm{~g}$ of proteins is recommended, which should also be maintained during the breastfeeding period $[14,16]$.

Iron: The iron present in plant foods is available in the non-heme form, which has less absorption by the human body when compared to the heme form contained in meat and meat products $[17,18,19]$. This less absorption would be a protective effect of the organism because when in excess it has an inflammatory and pro-oxidant effect, being an additional risk factor for the development of cardiovascular diseases and cancer [19,20]. The bioavailability of heme and non-heme iron varies according to the study analyzed $[17,18,19]$ and a systematic review showed that the amount of iron absorbed also varies according to the individual's iron stock and the type of meal consumed [18]. Individuals with low iron stores would have better absorption of iron and the balance between stimulating factors (vitamin $\mathrm{C}$ and other organic acids, carotene) and inhibitory factors (phytates and tannins) from the absorption of non-heme iron would determine the amount of iron absorbed in a given meal [17]. The Department of Nutrition and Food and the US Institute of Medicine consider the bioavailability of iron to be $10 \%$ in vegetarian diets and $18 \%$ in diets containing meat, with an $80 \%$ higher consumption in vegetarian diets being suggested because of this lower bioavailability, which can be achieved with a strictly wellplanned vegetarian diet $[1,20,21]$. In pregnancy, the plasma volume increases, leading to hemodilution with a decrease in hemoglobin $(\mathrm{Hb})$ values, being accepted as normal levels up to $11 \mathrm{~g} / \mathrm{dL}$ in the $1 \mathrm{st}$ trimester and $10.5 \mathrm{~g} / \mathrm{dL}$ in the 2 nd and 3rd trimesters $[1,14,16]$. On the other hand, iron requirements increase considerably during pregnancy and it is recommended to supplement $30 \mathrm{mg}$ of iron daily for all pregnant women since the beginning of pregnancy, regardless of the type of diet adopted, to prevent anemia, prematurity, and low weight $[2,14,16]$. The RDA ("Recommended Dietary Allowances") for iron during pregnancy is $27 \mathrm{mg}$ /day $[21,22]$. Also, it is very important to provide nutritional guidance to encourage the consumption of foods rich in iron (beans and dark green vegetables combined with foods rich in vitamin $\mathrm{C}$ or beta-carotene) $[1,16]$. The iron does to be supplemented in case of deficiency or pre-gestational anemia should be assessed individually based on the levels of ferritin and $\mathrm{Hb}$ found. During the breastfeeding period, iron needs return to pre-pregnancy values and a new assessment of iron stores is recommended $[1,16]$. A strict, well-planned vegetarian diet can easily meet the nutritional iron demands of lactating women [16].

Zinc: The main sources of zinc in vegetarian diets are grains, legumes, and oilseeds, but the high content of phytates and fibers in these foods decreases their absorption and although some studies $[23,24,25]$ have not observed significant differences between blood levels of zinc among vegetarians and non-vegetarians, a 50\% higher intake of this mineral in a vegetarian diet is recommended $[2,14,16]$. Zinc requirements are increased during pregnancy and vegetarian pregnant women should be advised to soak grains and legumes in water for at least 8 hours and consume zinc-source foods together with a vitamin C-rich food to improve its bioavailability mineral $[1,2,16,25]$.

B12 vitamin: Vitamin B12 is only found in foods of animal origin; fermented foods, spirulina, algae, and mushrooms are not reliable sources as it contains a similar form of B12 that is biologically inactive.Vitamin B12 needs are increased during pregnancy and every pregnant woman, regardless of the diet adopted, should have their vitamin B12 levels monitored throughout pregnancy. Levels considered to be optimal are above $487 \mathrm{pg} / \mathrm{mL}$ [26]. Low blood levels during pregnancy are associated with neural tube defects (levels below $300 \mathrm{pg} / \mathrm{mL}$ ), increased risk of spina bifida (levels below 250 $\mathrm{pg} / \mathrm{mL}$ ), low birth weight, delayed intrauterine growth, and delivery premature [13,27-30]. Strict vegetarian pregnant women should always be supplemented because the levels of this vitamin in breast milk and the infant's blood seem to be directly related to intake since the beginning of pregnancy $[1,27,28,30]$. A strict vegetarian diet will only be considered balanced if this supplementation of B12 is guaranteed thus allowing a pregnancy and fetal development within the normal range, without the risks observed when there is a deficiency of this vitamin $[1,13,27]$. The RDA for B12 is $2.6 \mathrm{mcg} /$ day during pregnancy and $2.8 \mathrm{mcg} /$ day during breastfeeding, but the suggested dose for supplementation is $50 \mathrm{mcg} /$ day for pregnant women and strict vegetarian lactating women $[1,27,28]$.In cases of deficiency, the suggested dose for treatment is $1000 \mathrm{mcg} /$ day, varying the treatment time according to the serum levels found (Table 1) [1].

Folate: A balanced vegetarian diet is rich in folate and the suggested supplementation for pregnant women and strict vegetarian lactating 
Table 1. B12 supplementation according to the serum levels found

\begin{tabular}{|c|c|c|c|c|}
\hline Serum B12 level & $<102 \mathrm{pg} / \mathrm{mL}$ & $\begin{array}{l}\text { between } 102 \text { and } \\
203 \mathrm{pg} / \mathrm{mL}\end{array}$ & $\begin{array}{l}\text { between } 203 \text { and } \\
298 \mathrm{pg} / \mathrm{mL}\end{array}$ & $\begin{array}{l}\text { between } 298 \text { and } \\
407 \mathrm{pg} / \mathrm{mL}\end{array}$ \\
\hline $\begin{array}{l}\text { Pregnant and } \\
\text { Lactating }\end{array}$ & $\begin{array}{l}1000 \mu \mathrm{g} / \text { day } \\
(4 \text { months })\end{array}$ & $\begin{array}{l}1000 \mu \mathrm{g} / \text { day } \\
(3 \text { months })\end{array}$ & $\begin{array}{l}1000 \mu \mathrm{g} / \text { day } \\
(2 \text { months })\end{array}$ & $\begin{array}{l}1000 \mu \mathrm{g} / \text { day } \\
(1 \text { month })\end{array}$ \\
\hline
\end{tabular}

women is the same indicated for women who consume foods of animal origin [31]. The RDA for folate during pregnancy is 600 $\mathrm{mcg} / \mathrm{day}$ and during the breastfeeding phase, it drops to $500 \mathrm{mcg} / \mathrm{day}$, with the supplementation of $400 \mathrm{mcg} / \mathrm{day}$ of folic acid being recommended as a way of preventing neural tube defects, in addition to consumption of foods rich in this vitamin (green leaves, legumes, citrus fruits), since 1 month before conception [14,22]. In the breastfeeding phase, the dose to be supplemented is the same suggested during pregnancy, higher doses did not show additional benefits or a significant increase in breast milk [32].

Essential Fatty Acids: Fatty acids of the type omega 3 (alphalinolenic acid -ALA) and omega 6 (linoleic acid - LA) are obtained exclusively through food. LAis converted to arachidonic acid (AA) and ALA is converted to docosahexaenoic acid (DHA) and eicosapentaenoic acid (EPA). The conversion of ALA to DHA is carried out by the same enzyme responsible for converting LA to AA, so an LA/ALA ratio of no more than 4: 1 is recommended, which is possible by limiting the intake of oils rich in omega 6 as corn and sunflower oils. The consumption of oils rich in saturated fats (coconut and palm) should also be avoided $[2,16]$. Direct sources of DHA are found only in foods of animal origin (cold water fish), so vegetarians should consume sources of ALA to obtain DHA. The biggest sources of ALA in the diet are flaxseed oil and flaxseed and chia seeds $(100 \mathrm{~mL}$ of flaxseed oil provides about $50 \mathrm{~g}$ of alphalinolenic acid) [33,34]. DHA is transferredtransplacentally to the formation of cell membranes in the fetal brain and retina and is essential for optimal neurological and visual development [16].The use of DHA supplements from algae during pregnancy and lactation is recommended regardless of the type of diet adopted by the pregnant woman due to its importance and potential risks caused by the ingestion of heavy metals such as mercury present in its direct sources $[1,2,14,35]$. Also, the rate of conversion of omega-3 to DHA during pregnancy is uncertain and the concentration of DHA in breast milk depends on the mother's nutritional status. The suggested dose for supplementation is $200 \mathrm{mg} /$ day $[1,14,35]$.

Vitamin D: The greatest source of vitamin D is sun exposure and foods rich in this vitamin (fish liver oil, tuna, sardines, liver), in addition to not being routinely consumed, contribute less than $10 \%$ of the daily needs of this vitamin [36]. During pregnancy, there is no increase in vitamin D demand, but it is suggested that serum $25(\mathrm{OH})$ $\mathrm{D}$ levels be evaluated even before conception due to the deleterious effects of hypovitaminosis $\mathrm{D}$ during pregnancy and the blood level considered sufficient is above $20 \mathrm{ng} / \mathrm{mL}[1,16,37-39]$. The supplementation of $600 \mathrm{IU} /$ day is indicated for all pregnant women as a way of preventing maternal and neonatal deficiency and its consequences (rickets and osteomalacia in childhood), since the blood levels of this vitamin in the NB are directly related to maternal blood levels [1,16, 37,38]. Some articles suggest blood levels above $30 \mathrm{ng} / \mathrm{mL}$ and supplementation of slightly higher doses (1000$200 \mathrm{UI} /$ day) $[1,2,38,39]$. Supplementation of doses up to $4000 \mathrm{IU} /$ day is considered safe for pregnant women and most experts suggest doses of 1000 to $2000 \mathrm{IU} /$ day in cases of deficiency $[1,14,39]$.Vitamin D supplementation for vegetarian pregnant women should be done via lichen cholecalciferol ("vegan D3") or via ergocalciferol (D2), both with similar efficacy in the doses recommended here $[1,2]$. Vitamin D3 routinely used is obtained from the fat of the lamb and the vegetarian or vegan pregnant woman may not agree with this form of supplementation. During the breastfeeding phase, this supplementation should be maintained as a way to supply maternal demand and maintain adequate blood levels and not as a form of supplementation of the infant via breast milk [37].
Calcium: During pregnancy, there is a greater absorption of calcium by the maternal organism so that even with a greater demand the amount of calcium to be ingested is the same as in the pre-gestational period $[16,37,40]$.Strict vegetarian pregnant women should consume around 1200 to $1300 \mathrm{mg}$ of calcium per day, which corresponds to $20 \%$ more than omnivorous pregnant women due to a probable lower bioavailability of this mineral in a diet without any animal food $[16,40,41]$. If the pregnant woman consumes less than $500 \mathrm{mg} /$ day of calcium, maternal and fetal needs may be compromised $[16,40]$. Calcium supplementation is indicated only in cases where an intake below the recommended amount is found [16].The calcium present in human milk originates from the resorption of the maternal skeleton and even a low calcium intake during the breastfeeding phase does not affect the calcium content present in the milk nor does it increase maternal bone loss. Likewise, the ingestion of high doses of calcium is not effective in reducing bone resorption that occurs during lactation $[42,43]$

\section{FINAL CONSIDERATIONS}

A strict, well-planned vegetarian diet is perfectly capable of meeting all nutritional demands during pregnancy and lactation. Special attention should be paid to vitamin B12 supplementation, the only nutrient not found in foods of plant origin and great importance for the neurological development of the fetus and infant. Unfavorable outcomes observed in strict vegetarian pregnant women occurred due to nutritional deficits generated by a poorly planned diet and without guidance from a specialized professional. Health professionals, especially doctors, must be up to date on the peculiarities surrounding a strict vegetarian diet to know how to implement the necessary nutritional adjustments during pregnancy and lactation, guiding which foods the pregnant woman should prioritize and indicating the supplementation of the most critical nutrients. when food is not able to supply them in full, as is the case with vitamin B12. A strict vegetarian diet to be considered healthy must be well planned and balanced, following the criteria discussed here. The simple fact of excluding animal foods from the diet cannot serve as a "model" when talking about this type of diet. Poorly planned strict ("vegan") vegetarian diets without an adequate and balanced choice of foods, without vitamin B12 supplementation and assessment of the most critical micronutrients such as DHA, iron, and calcium, will certainly not meet the nutritional demands of pregnant and lactating women as well. as a diet with foods of animal origin but without vegetables, greens and fruits can also bring many damages to the pregnant woman and the fetus. Every health professional must be able to respect the food choices of their patients and have sufficient knowledge to understand that the exclusion of foods of animal origin will only be a risk factor for the development of nutritional deficits if it is not well conducted by the professional who is ahead of the case.

Declaration of Potential Conflict of Interest: The authors declare no conflict of interest.

Funding: Not applicable.

Data Sharing Statement: No additional data are available.

\section{REFERENCES}

Abu-Assal MJ\& Craig WJ. The zinc status of pregnant vegetarian women. Nutrition Reports International, 1984, 29(2), 485-494. 
ACOG Committee on Obstetric Practice. ACOG Committee Opinion No. 495: Vitamin D: Screening and supplementation during pregnancy. Obstet. Gynecol. 2011, 118, 197-198.

Agnoli C,Baroni L,Bertini I, Ciappellano S,Fabbri A, Papa M.; et al. Position paper on vegetarian diets from the working group of the Italian Society of Human Nutrition. Nutr. Metab. Cardiovasc. Dis. 2017, 27, 1037-1052

Almeida CAN, Ribas Filho D, Mello ED, et al. Consenso da Associação Brasileira de Nutrologia sobre Recomendações de DHA durante a Gestação, Lactação e Infância. InternationalJournalofNutrology. Setembro, 2014.

Amit M. Vegetarian diets in children and adolescents; Canadian Paediatric Society; Community Pediatrics Committee; Position Statement; jun, 1, 2010, Reaffirmed: feb 28, 2018.

Baroni L, Goggi S, Battaglino R, Berveglieri M, Fasan I, Filippin D, Griffith P, Rizzo G, Tomasini C, Tosatti MA, Battino MA. Vegan Nutrition for Mothers and Children: Practical Tools for Healthcare Providers. Nutrients. 2018 Dec 20;11(1):5. doi: 10.3390/nu11010005. PMID: 30577451; PMCID: PMC6356233.

Berkow SE, Barnard ND. Blood pressure regulation and vegetarian diets. Nutr. Rev. 2005, 63, 1-8.

Collings R, Harvey LJ, Hooper L et at. The absorption of iron from whole diets: a systematic review. Am J ClinNutr 2013;98:65-81.

Duggan C. et al. Vitamin B12 Supplementation during Pregnancy and Early Lactation Increases Maternal, Breast Milk, and Infant Measures of Vitamin B -12 Status. J.Nutr. 144: 758 -764, 2014.

Fewtrell M,Bronsky J,Campoy C,Domellöf M,Embleton N,FidlerMis N,Hosjak I,Hulst JM, Indrio F,Alexandre L.; et al. Complementary Feeding: A Position Paper by the European Society for Paediatric Gastroenterology, Hepatology, and Nutrition (ESPGHAN) Committee on Nutrition. J. Pediatr. Gatroenterol. Nutr. 2017, 64, 119-132.

Fonseca-Nunes A, Jakszyn P, Agudo A. Iron and Cancer Risk - A Systematic Review and Meta-analysis of the Epidemiological Evidence. Cancer Epidemiol Biomarkers Prev; 23(1) January 2014.

Food and Nutrition Board, and Institute of Medicine. (2001). Dietary Reference Intakes for Vitamin A, Vitamin K, Arsenic, Boron, Chromium, Copper, Iodine, Iron, Manganese, Molybdenum, Nickel, Silicon, Vanadium, and Zinc. National Academy Press, Washington, DC.

Foster M, Samman S. Vegetarian diets across the lifecycle: Impact on zinc intake and status. Adv. Food. Nutr. Res. 2015, 74, 93-131.

Groenen PM, Van Rooij IA, et al. Marginal maternal vitamin B12 status increases the risk of offspring with spina bifida. Am J ObstetGynecol 2004 Jul;191(1):11-7.

Guastamacchia E,Triggiani V, Aglialoro A, Aiello A, Ianni L,Maccario M, Zini M, Giorda C, Guglielmi R,Betterle C et al. Italian Association of Clinical Endocrinologists (AME) and Italian Chapter of the American Association of Clinical Endocrinologists (AACE) Position Statement: Clinical Management of Vitamin D Deficiency in Adults. Nutrients 2018, 10, 546.

Hacker AN, Fung EB, King JC. Role of calcium during pregnancy: maternal and fetal needs. Nutr. Rev. 2012, 70(7):397-409.

Haider LM,Schwingshackl L, Hoffmann G, Ekmekkcioglu C. The effect of vegetarian diets on iron status in adults: A systematic review and meta-analysis.Crit. Rev. Food Sci. Nutr. 2016, 23, 116.

Herrmann W, et al. Vegetarian lifestyle and monitoring of vitamin B12 status. ClinChimActa. 2002 Dec;326(1-2): 47-59.

Hurrell R, Egli I. Iron biovailability and dietary reference values. Am J ClinNutr 2010;91(suppl): 1461S-7S.

Institute of Medicine. Dietary Reference Intakes: The Essential Guide to Nutrient Requirements. Washington DC: The National Academies Press; 2006.

King JC, Stein T, Doyle M. Effect of vegetarianism on the zinc status of pregnant women. Am J ClinNutr 1981;34:1049-55.
Kovacs, CS. Calcium and Bone Metabolism Disorders During Pregnancy and Lactation. Endocrinology and Metabolism Clinics of North America, 2011;40(4), 795-826.

Mangels AR, Messina V, Considerations in planning vegan diets: infants. Journal of American Dietetic Association; jun, 2001; volume $101, \mathrm{~N}^{\mathrm{o}} 6 ; 670-677$.

MangelsAR. Bone nutrients for vegetarians. Am J ClinNutr 2014;100(suppl):469S-75S.

Melina V, Craig W, Levin S. Position of the Academy of Nutrition and Dietetics: Vegetarian Diets. J AcadNutr Diet. 2016;116:1970-1980.

Munns CF, Shaw N,Kiely M,Specker BL, Thacher TD, Ozono K,Michigami T,Tiosano D,Mughal MZ, Ramos-Abad L et al. Global Consensus Recommendations on Prevention and Management of Nutritional Rickets. J. Clin. Endocrinol. Metab. 2016, 101, 394-415.

Nutritional Aspects of Vegetarian Diets American Academy of Pediatrics. In: Kleinman RE, Greer FR. Eds. Pediatric Nutrition, 7th Ed. ElkGrove Village, IL: American Academy of Pediatrics; 2014, 241-264.

Page R, Robichaud A, et al. Total folate and unmetabolized folic acid in the breast milk of across-section of Canadian women. Am J ClinNutr 2017;105:1101-9.

Pawlak R. et al. Vitamin B12 content in breast milk of vegan, vegetarian, and nonvegetarian lactating women in United States. Am J ClinNutr 2018; 108:1 -7.

Pawlak R. To vegan or not to vegan when pregnant, lactating or feeding young children. Eur. J. Clin. Nutr, 2017; 71: 1259-1262.

Piccoli GB, Vigotti FN, Leone F, et al. Vegan-vegetarian diets in pregnancy: danger or panacea? A systematic narrative review. BJOG 2015; 122:623-633.

Procter SB, Campbell CG. Position of the Academy of Nutrition and Dietetics: Nutrition and lifestyle for a healthy pregnancy outcome. J AcadNutr Diet, 2014; 114(7):1099-1103.

Rosell M, Appleby P, Spencer E, Key T. Weight gain over 5 years in 21,966 meat-eating, fish-eating, vegetarian, and vegan men and women in EPIC-Oxford. Int. J. Obes. 2006, 30, 1389-1396.

Saadi HF; Dawodu A.; Zayed R.; et al. Efficacy of daily and monthly high-dose calciferol in vitamin $\mathrm{D}$ - deficient nulliparous and lactating women. Am J ClinNutr 2007;85:1565-71.

Sebastini G, Barbero AH, et al. The Effects of Vegetarian and Vegan Diet during Pregnancy on the Health of Mothers and Offspring. Nutrients, 2019, 11, 557; doi:10.3390/nu11030557.

Siddiqua TJ, Allen LH, Raqib R, Ahmed T. Vitamin B12 Deficiency in Pregnancy and Lactation: Is there a Need for Pre and Postnatal supplementation? J Nutr Disorders Ther 2014, 4:2

Simpson JL, Bailey LB et al. Micronutrients and women of reproductive potential: required dietary intake and consequences of dietary deficiency or excess. Part I - Folate, Vitamin B12, Vitamin B6. J Maternal Fetal Neonatal Med. 2010 Dec;23(12):1323-43.

Sociedade Brasileira de Pediatria. Departamento de Nutrologia. Deficiência de vitamina D em crianças e adolescentes; Documento Científico, 2015.

Specker B. Nutritional concerns of lactating women consuming vegetarian diets; AM J Clin Nutr.1994; 59 (supl.); 1182S-1186S.

Tabela Brasileira de composição de alimentos. Disponível em: http://www.nepa.unicamp.br/taco/contar/taco_4_edicao_ampliad a_e_revisada.pdf?arquivo=taco_4_versao_ampliada_e_revisada. pdff, último acesso em 20/06/19.

United States Department of Agriculture. Agricultural Research Service. USDA Food Composition Databases. Disponível em https://ndb.nal.usda.gov/ndb/nutrients, último acesso em 20/06/19.

Wang F,Zheng J, Yang B, Jiang J, Fu Y, Li D. Effects of Vegetarian Diets on Blood Lipids: A Systematic Review and Meta-Analysis of Randomized Controlled Trials. J. Am. Heart. Assoc. 2015, 27, e002408.

Young V, Pellett P. Plant proteins in relation to human protein and amino acid nutrition. Am J ClinNutr 1994:59; 1203S-1212S. 